\title{
Trial Application of Acceptance and Commitment Therapy Principles to Reduce the Degree of Stress Experienced by Adolescents with Down Syndrome Sibling(s)
}

\author{
Afada Alhaque, Poeti Joefiani ${ }^{2}$, Esti Wungu ${ }^{3}$ \\ ${ }^{1}$ Faculty of Psychology, Universitas Padjadjaran; Jl. Raya Bandung - Sumedang KM 21, Jawa \\ Barat, 45363, (022) 7794126 \\ nanahaque.nh@gmail.com,jpoeti@yahoo.com, esti.wungu@unpad.ac.id
}

\begin{abstract}
This study was conducted to see whether the training module of the application of the principle of Acceptance and Commitment Therapy can be used as an intervention to reduce the stress degree of adolescents aged $14-16$ who have Down Syndrome's sibling. The design of this research is quasi-experiment with One Group Pretest - Posttest Design method. The sample of the study were three adolescents aged 14-16 who had Down Syndrome's sibling, were obtained by purposive sampling technique. The measuring tool used in this study is the Stress Degrees questionnaire, based on stress theory by Lazarus and Folkman (1984), to measure the stress degree, and the Acceptance and Action Questionnaire II (AAQ-II) questionnaire to measure psychological flexibility, adapted into Indonesian from AAQ-II (Hayes, et al, 2004). The results showed that the application of the ACT principle significantly reduced the stress degree and increased the psychological flexibility of adolescents aged $14-16$ who have Down Syndrome's sibling, with a significance value of 0.016 (sig <0.05). Through the application of ACT principles, the subjects's psychological flexibility is increased so that the subjects know how to deal with problems, by accepting negative or unpleasant feelings and thoughts because of having Down Syndrome's sibling and having a commitment to achieve goals according with their value of life.
\end{abstract}

Keywords: Acceptance and Commitment Therapy (ACT); Stress Degree; Psychological Flexibility; Adolescents with Down Syndrome's Sibling

\section{Introduction}

Down Syndrome is one of the most common forms of intellectual disability that emerges and occurs since birth (Beirne-Smith, Patton, \& Kim, 2006, in Hallahan, Kaufman, \& Pullen, 2009). Research on Down Syndrome revealed that there are three chromosome separations that cause this syndrome, namely translocation on chromosomes 13 and 15 pairs, variations in the number of cells within the chromosomes, and trisomy on chromosome 21 (Mash \& Wolfe, 2010). Down Syndrome presents serious problems for the afflicted. Children with Down Syndrome can have mental retardation, a distinctive facial shape, poor muscle tone (hypotonia) during infancy, and learning difficulties throughout their development.
The presence of family member with a disability will affect all family members (Wright, Watson, and Bell, 1996, in Wilkerson, 2001), including the sibling(s) of Down Syndrome children. Children who have sibling(s) with Down Syndrome tend to have different type and pattern of relationship compared to the children who have typically developing sibling(s), especially when they enter adolescence.

Adolescents, especially with the broadening of their social world, are very concerned about how their peers think about what happened to their disabled sibling(s) (Burke, 2004). The condition of having sibling(s) with Down Syndrome sibling(s) can make teens often experience negative views and receive comments related to their Down 


\section{Trial Application of Acceptance and Commitment Therapy ... Afada Alhaque', Poeti Joefiani ${ }^{2}$, Esti Wungu ${ }^{3}$}

Syndrome sibling(s). The sensitivity of adolescents to peer opinions and environmental opinion, makes teens feel depressed by the condition of having Down Syndrome sibling(s). Because teenagers think that most other friends do not have sibling(s) with Down Syndrome, so teenagers consider themselves different than their peers and their environment. Teenagers also feel ashamed, sad, and tend to avoid social interaction with friends because of the negative views and comments that teens receive related to the condition of having Down Syndrome sibling(s). Usually, a typically developing adolescents experience a lot of stress in interactions with their sibling(s) who have Down Syndrome (Fisman, 2000, in Sullivan, 2002).

Stress is an internal state of condition that can be caused by physical demands from the body or environmental and social conditions that are considered potentially dangerous, out of control, or exceeding the ability of individuals to overcome them (Lazarus and Folkman, 1984). There are individual differences in the assessment on whether or not a teen was stressed about the situation they face daily with their Down Syndrome sibling(s). Each individual has a different cognitive appraisal of situations that can cause stress (Lazarus and Folkman, 1984). This appraisal then raises different degrees of stress. The degree of stress is the level of stress experienced due to a primary appraisals (initial appraisal of an event), and secondary appraisals which depends on the resources and choice of coping strategies of a person (Lazarus and Folkman, 1984). The degree of stress experienced can arise in the form of physiological, cognitive, emotional, or behavioral responses (Sarafino and Smith, 2011).

Based on the initial interviews with three teenagers aged 14-16 who have Down Syndrome sibling(s), it is revealed that teens become angry and upset both toward their parents who ask teens to look after their Down Syndrome sibling(s), or toward their Down Syndrome sibling(s) who have limited abilities so that they need more supervision compared to a typically developing siblings.
Adolescents assess the condition of having Down Syndrome siblings as a stressful and negative conditions (primary appraisals). Adolescents judge that they do not have the appropriate resources to deal with the stressors, because adolescents assess that by having a sibling(s) with Down Syndrome they become different compared to their friends who do not have sibling(s) with Down Syndrome (secondary appraisals). Such appraisals elicit some form of response to the degree of stress that adolescents experience due to their condition. The initial interviews was conducted using guided interviews based on stress theory by Lazarus and Folkman (1984), which are associated with the condition of adolescents having sibling(s) with Down Syndrome.

Some forms of stress response that arise includes cognitive responses, emotional responses, and behavioral responses. Cognitive response such as feeling different compared to their friend and preoccupation with thoughts concerning their own condition makes it difficult to think of anything else and may hinder their ability to concentrate in school. Emotional responses such as anger, shame, and sadness that arises du to the cynical view or general dislike toward their Down Syndrome sibling(s). Behavioral response includes avoidance, for example, avoiding going out of the house with their Down Syndrome sibling(s) to reduce the possibility of being seen by friends, or avoid to invite their friends to play at their house, so their friends do not need to see their Down Syndrome siblings. They also avoid avoid showing photos with their Down Syndrome sibling(s) to others.

Seeing the presence of negative cognitions, and emotions that arise as a response to stress in adolescents related to their condition of having a Down Syndrome sibling, it is important to conduct psychological interventions so that they can cope with their stress. Acceptance and Commitment Therapy (ACT) was chosen as an intervention in this study due to its' nature as stress reduction interventions (Hayes and Strosahl, 2004). In addition, ACT is also developmentally appropriate for adolescents, because the ACT can help them to deal with 


\section{Trial Application of Acceptance and Commitment Therapy ... Afada Alhaque', Poeti Joefiani ${ }^{2}$, Esti Wungu ${ }^{3}$}

their emotions, connect with others, deal with fear, achieve goals, and help them to achieve optimal development (Harris, 2016). The use of Metaphors that features heavily in ACT is appropriate with the formal operational stages of cognitive development of an adolescent that enables them to understand abstract concepts. In addition, metaphors is also free of judgment so that teens do not feel judged, either right or wrong, about their appraisals or negative feelings related to their conditions. Learning media in the form of experimental work are also suitable to help adolescents better understand themselves and understand the process of change that occurs while participating in ACT activities. ACT also invites adolescents to not only deal with problems but also to find the true values that exist within them to enable them to develop optimally.

ACT invites an individual to perform reappraisal to the possible ways that can be done to deal with a threatening situation. This reappraisal can be achieved because ACT enables them to get new information about the source of the stressor and ways that can be done to deal with the stressor, by accepting and being able to live based on values. Common strategies used in ACT is by teaching psychological abilities effectively deal with negative thoughts or feelings in the way that has the least negative impact. Then help individuals clarify what is really the most important and most meaningful to them (find values), and use that to guide, inspire, and motivate them to change lives for the better.

There are six principles in ACT, namely acceptance, cognitive defusion, being present, self as context, values, and committed action. Adolescents are expected to accept negative feelings and thoughts related to the condition of having a Down Syndrome sibling(s) (acceptance), reduce control of negative thoughts and feelings within them (cognitive defusion), focus on dealing with current experiences without worrying too much about the possibility of a bad future (being present), and able to see themselves objectively (self as context). At the last stage, adolescents are then invited to find what things they want in life, namely what they want to spend their life time on, what matters most, and what makes them able to survive (values), and committed to achieve their objectives (commited action).

Through the ACT's six principle processes it is expected that adolescents who have Down Syndrome siblings can accept the conditions of having Down Syndrome sibling(s), know that they have the resource to deal with the situation, have goals to be achieved, and are committed to achieving them. Adolescents are expected to have high psychological flexibility, so they have the ability to face unpleasant conditions accompanied by openness and awareness, and able to behave in accordance with self-values. The higher the psychological flexibility of adolescents, the more adolescent's quality life increases and become optimal.

Based on the explanation above, the null hypothesis $\left(\mathrm{H}_{0}\right)$ of this study is that there is no reduction in the degree of stress before and after the training to apply Acceptance and Commitment Therapy principles on adolescents with Down Syndrome sibling(s). While the alternative hypothesis $\left(\mathrm{H}_{1}\right)$ for this study is decreasing degree of stress after the training compared to prior measurement.

\section{Methods}

This research employs quasiexperimental design with the one group pretest-posttest design method. In quasiexperimental research, there are several situations that cannot be controlled (Christensen, 2007). With this design, we would measure the effect of treatment by comparing the reaction pattern prior the treatment, with the reaction pattern after the treatment was given to the subject Christensen, 2007).

The application of Acceptance and Commitment principles used in this study was designed in the form of a module. The training modules used are based on the principles of Acceptance and Commitment as stated by Hayes, et.al (1999). The modules consists of metaphors, discussion guides, and worksheets that will be worked by research subjects. The metaphors and exercises used in the training module are chosen based on the suitability to 
the degree of stress experienced by the subject, and tailored in accordance to their comprehension abilities.

This research also uses mixed-method, which is a method that applies a combination of two approaches at once (qualitative and quantitative) (Creswell, 2013). The mixedmethod strategy used in this study is a concurrent embedded strategy, which implements one stage of quantitative and qualitative data collection at one time (Creswell, 2013). In this study, quantitative methods as primary methods will be used to explain the expected outcomes of the training process, while qualitative data as secondary methods, will be used to explore the processes experienced by each subject.

Subjects invloved in this study, are adolescents aged 14-16 years who have Down Syndrome sibling(s) whom attend SLB C Palembang, have moderate or high levels of stress based on a stress degree questionnaire based on the dimensions proposed by Lazarus and Folkman (1984), has a low level of psychological flexibility based on AAQ-II, and has average to high level of intelligence (based on intelligence standards in Standard Progressive Matrices) to ensure the subject has a good abstraction ability so that the subject is able to comprehend the metaphors given during the intervention. The number of subjects in the study consisted of three subjects, with two boys, and one girls. Two of them are $1^{\text {st }}$ year high school students aged 15 years old, and the other is $3^{\text {rd }}$ year junior high school students aged 14 years old.

Instruments used in this study are the Stress Degrees Scale (consisting of 53 items), which were developed by us based on the stress theory proposed by Lazarus and Folkman (1989), as well as Acceptance and Action Questionnaire - II (AAQ - II) from Bond, et.al (2011) that consists of 10 items to measure psychological flexibility, which adapted into Bahasa Indonesia by us. Both measurement instruments used as a pretest and posttest. Reliability estimation of the Stress Degrees Sclae uses alpha cronbach estimation
(0.931; high reliability), and the AAQ-II (0.683; moderate reliability). This demonstrates that the both instruments can measure the degree of stress and psychological flexibility consistently. The validity test of the two measuring instruments is carried out with content validity by expert judgment.

Data analysis techniques in this study were carried out quantitatively and qualitatively. Quantitative data analysis techniques are carried out with descriptive statistics and significance tests to see whether the changes that occur from the data obtained can be accepted, applicable, and can be generalized to the population. The level of significance used in this study was $5 \%$, which means that the probability of the correct results of the significance test of this study is around $95 \%$. While the qualitative analysis uses content analysis to analyze the results. Content analysis is done to examine the subject's behavior, thoughts, and feelings (Breakwell, Smith, and Wright, 2012). The analysis was performed using thematic analysis, which is an analysis technique used by looking at a theme or pattern (Glesne, 2011) obtained from observations and interviews. From the results of the analysis, we can evaluate whether the results of the study are in accordance with the objectives of each training session or not.

\section{Findings and Discussion}

\section{Findings}

Within diagram 1 below we can see the results of the pre-test and post-test of the three research subjects. It can be seen that each posttest score from the subject's degree of stress is lower compared to the pre-test score. Which means that there is a decrease in the degree of stress that the subject experiences after receiving the training on the application of Acceptance and Commitment Therapy principle. 
Trial Application of Acceptance Afada Alhaque ${ }^{1}$, Poeti Joefiani ${ }^{2}$, Esti Wungu ${ }^{3}$

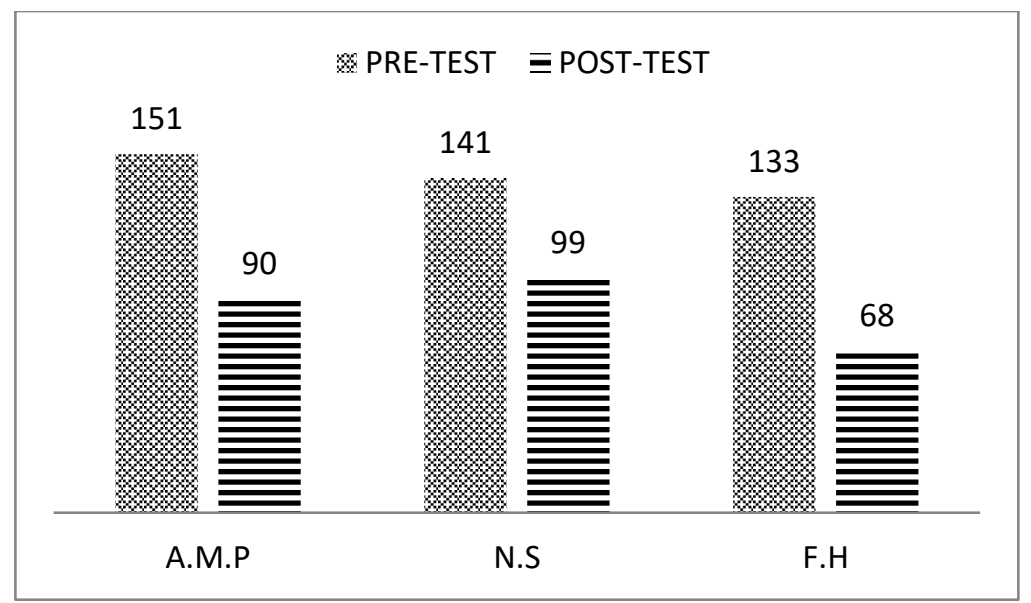

Diagram 1. Results of Pre-Test and Post-Test Stress Degrees

Researchers also conducted significance tests using the Paired T-Test. To see whether the reduction in the degree of stress that occurs after the training is given is significant. From table 1. it can be seen that $\mathrm{t}$ value is 7.893 and the significance is .016 (Sig <0.05). Which means that there is a significant reduction in the degree of stress after the training was given $\left(\mathrm{H}_{0}\right.$ from this study was rejected and
$\mathrm{H}_{1}$ from this study was accepted). Furthermore, diagram 2. it is revelaed that post-test score from AAQ-II measurement is higher compared to the pre-test score. Before attending the training, the subjects have low psychological flexibility. While after attending the training, there are improvement, so that they have high psychological flexibility.

\begin{tabular}{|c|c|c|c|c|c|c|c|}
\hline & & Mean & Std.Deviation & Std.Error & $\mathbf{t}$ & df & $\begin{array}{c}\text { Sig. } \\
\text { (2-tailed) }\end{array}$ \\
\hline $\begin{array}{r}\text { Pair } \\
1\end{array}$ & $\begin{array}{l}\text { PRETEST- } \\
\text { POSTTEST }\end{array}$ & 1.05660 & .23185 & .13386 & 7.893 & 2 & .016 \\
\hline
\end{tabular}




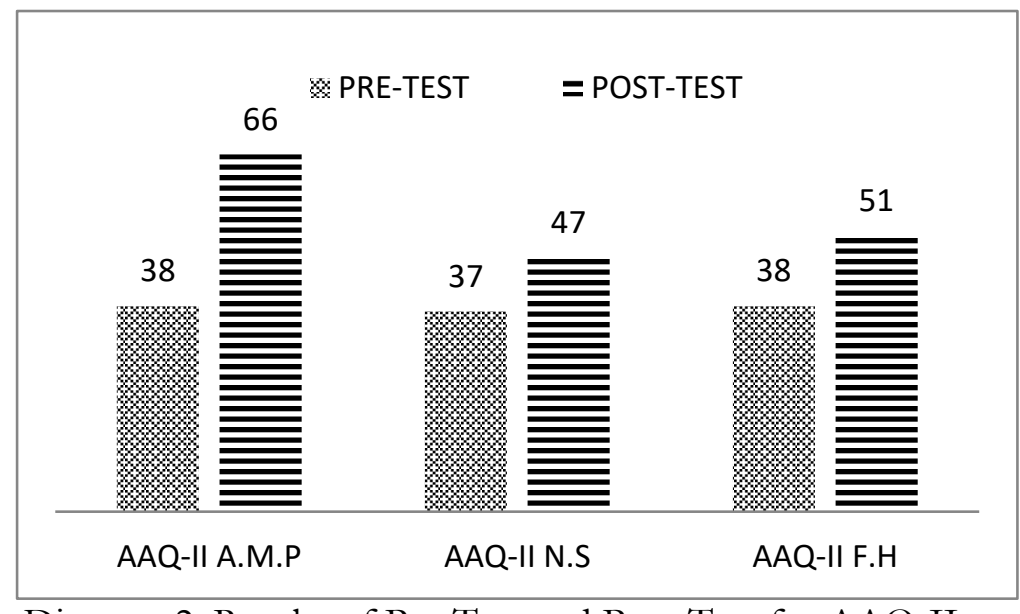

Diagram 2. Results of Pre-Test and Post-Test for AAQ-II

From the results of a descriptive analysis it can be seen that there is a decrease in the degree of stress in the three subjects between pre-test and post-test scores. This reduction in stress level was proven to be significant with a $t$ value of 7,893 and a significance of 0.016 (Sig $<0.05)$, which means that training in the application of the principle of Acceptance and Commitment Therapy could significantly reduce the stress degree of adolescents who have Sibling(s) with Down Syndrome. From the results of the descriptive analysis it can also be seen that there is an increase in the psychological flexibility of the subject, where before taking training, the psychological flexibility of the subject is in the low category, while after attending the psychological flexibility training the subject is in the high category.

\section{Discussion}

The decrease in degree of stress in subjects who participates in this study can be achieved because of the process received during the training in the application of the principles of Acceptance and Commitment Therapy. It is the result of reappraisals by the subject in response to new information about the source of the stressor and about how to deal with the stressor. Judging from the process experienced by the subjects from session I to session IV (Mindfulness and Acceptance Process), it was clear that through the metaphors and exercises given in each session, they gain confidence in their ability to control the situation related to their condition. They who had prior negative appraisals concerning their condition, and appraise that they did not have the necessary resources or ability to deal with these stressful conditions, gains new strategies in dealing with stressful situations other than resisting or avoiding.

They learn that there are more effective options for dealing with negative feelings and thoughts than resisting or avoiding, namely by accepting the situation, They also learn to control their mind so that psychological problems do not increase. Furthermore, they also realize that negative feelings and thoughts have no control in determining what they want to do, and that they can position themselves as an observer of their own feelings and thoughts without making negative feelings and thoughts an obstacle to achieve what they wants. As stated by Hayes, et al (2006), by reducing negative thinking (doing cognitive defusion) can lead to individuals having more positive beliefs about themselves.

The understanding and awareness elicited during sessions I - IV is belief factor that stimulates the occurrence of reappraisals. As stated by Lazarus and Folkman (1984), there are two important things in determining the occurrence of reappraisal, namely belief and commitment. Belief is a confidence to control the 
situation at hand (Lazarus and Folkman, 1984). This belief factor is successfully obtained by the subjects through the understanding and awareness that they receives from applying the principles of acceptance, being present, cognitive defusion, and self-as-context which are four of the six principles in Acceptance and Commitment Therapy.

Furthermore, in session V - VI (Commitment and Behavior Process), they recognize what is most important and most valuable to them (life value - values). Tthey are able to find goals to be achieved in accordance with the value of his life. They also gained an understanding that obstacles would surely exist in life, and it will arise in the process of achieving their goal. The most important thing is that they have a commitment to continue to pursue the goal even though there are some obstacles arises (such as negative and unpleasant feelings and thoughts related to having a Down Syndrome sibling(s)).

The understanding and awareness that they obtained from the V-VI (Commitment and Behavior Process) session is another factor that supports the reappraisal process, namely commitment. Commitment is a form of response about what is important for individuals and underlies individual's motivation to take action (Lazarus and Folkman, 1984). Through the principle of values (session V), they becomes aware of what is most important and most valuable to them (values), that motivates them to achieve the goal. Through the principle of commitment (session VI), they were also invited to understand the importance of having a commitment to achieve goals even though negative feelings and thoughts related to the condition of having Down Syndrome siblings might still appear in the subjects' daily lives.

From the application of the six principles of Acceptance and Commitment Therapy, subjects experienced a sharp increase in their psychological flexibility.
This shows that prior to participating in a series of six sessions in applying the principles of Acceptance and Commitment Therapy, all three subjects had difficulty dealing with negative or unpleasant feelings and thoughts that arises because they had a Down Syndrome sibling(s). With the increase in psychological flexibility after receiving training, it help them to accept the condition of having a Down Syndrome sibling(s) and to accept negative or unpleasant feelings and thoughts related it. The subject also becomes aware that he can still achieve the desired goals without focusing on negative feelings and thoughts, and has a commitment to achieve these desired goals.

These results are consistent with Hayes, et al (1999) proposal which states that Acceptance and Commitment Therapy can increase psychological flexibility, it can provide individuals have the ability to relate to daily life events with full awareness and ability to maintain behavior in accordance with the desired goals.

After participating in the training, reappraisals occur because the subject obtained a more effective ways to deal with negative or unpleasant feelings and thoughts regarding the condition of having Down Syndrome sibling(s). They also obtained the belief in their ability to control the situation at hand and knows what is important for them, that motivates them to take action, both of which are two important things in determining judgment (Lazarus and Folkman, 1984). In the end, each subjects appraised the condition of having Down Syndrome siblings as a neutral condition rather than depressing and negative condition. Furthermore, they did not let negative or unpleasant feelings and thoughts to hinder them on focusing to achieve their life goals.

Limitations of this study, includes the small number of samples, consisting only three subjects. Subsequent studies and further research should involves a larger number of samples, to evaluate and further 


\section{Trial Application of Acceptance and Commitment Therapy ... Afada Alhaque', Poeti Joefiani ${ }^{2}$, Esti Wungu ${ }^{3}$}

confirm the effectiveness of the intervention proposed in this study.

\section{Conclusion}

Based on the results and discussions, it can be concluded that the application of Acceptance and Commitment Therapy principle can significantly reduce the degree of stress and increase psychological flexibility in adolescents aged 14-16 years who have sibling(s) with Down Syndrome. Three subjects participated in the training were able to accept negative or unpleasant feelings and thoughts related to their condition of having a Down Syndrome sibling(s), and were able to make a commitment to achieve their life goals by no longer considering negative or unpleasant feelings and thoughts as an obstacle to achieve their goals.

\section{References}

Agochiya, D. 2002. Every Trainer's Handbook. Los Angeles: Sage.

American Psychiatry Association. (2013). Diagnostic and Statistical Manual of Mental Disorder (Fifth Edition ed.). Washington: American Psychiatric Publishing.

American Psychological Association. 2002. A Reference for Professionals: Developing Adolescents. Washington: American Psychological Association.

Arch, J., Craske, M.G. 2008. Acceptance and Commitment Therapy and Cognitive Behavioral Therapy for Anxiety Disorders: Different Treatments, Similar Mechanism? Clinical Psychology: Science and Practice Vol. 15 No. 4, 264-279.

Armstrong, A.B., Morrison, K.L., Twohig,M.P. 2013. A Preliminary Investigation of Acceptance and Commitment Therapy for Adolescent Obsessive-Compulsive Disorder.
Journal of Cognitive Psychoterapy: An International Quartely Vol. 27, No.2.

Barker, C., Pistrang, N., Elliot, R. 2002. Research Methods in Clinical Psychology $2^{\text {nd }}$ Edition. USA: John Wiley \& Sons.

Beirne-Smith, M., Patton, J., \& Kim, S. (2006). Mental Retardation. New Jersey: Pearson Education.

Berk, L.E. 2008. Infants, Children, and Adolescents $6^{\text {th }}$ Edition. New York: Pearson.

Bond, F.W. 2011. Preliminary Psychometric Properties of Acceptance and Action Questionnaire II: A Revised Measure of Psychological Inflexibility and Experiental Avoidance. Behavior Therapy, Vol. 42, 676-688.

Breakwell, G.M., Smith, J.A., Wright, D.B. 2012. Research Methods in Psychology $4^{\text {th }}$ Edition. London: SAGE Publication Ltd.

Budman, S.H., Gurman, A.S 1988. Theory and Practice of Brief Therapy. USA: The Guilford Press.

Christensen, L.B. 2007. Experimental Methodology $10^{\text {th }}$ Edition. New York: Pearson Education, Inc.

Cuskelly, M., Hauser-Cram, P., Riper, M.V.2010. Families of Children With Down Syndrome: What We Know And What We Need To Know. Down Syndrome Research and Practice, pg. 105113, doi: 103104/ reviews2079.

Dahl, Joanne C, et.al. 2009. The Art \& Science of Valuing in Psychotherapy Helpong Clients Discover, Explore, and Commit to Valued Action Using Acceptance Commitment Therapy. Oakland: New Harbinger Publication.

Fink, G. 2000. Encyclopedia of stress (Vol.1-3). San Diego: Academic Press.

Fledderus, M., Bohlmeiher, E.T., Smit. F., Westerhof. G.J. 2010. Mental Health Promotion as a New Goal in Public 
Mental Health Care: A Randomized Controlled Trial of an Intervention Enhancing Psychological Flexibility. American Journal of Public Health, Vol. 100, No. 12, 2372-2378.

Fletcher, L., Hayes, S.C. 2005. Relational Frame Theory, Acceptance, and Commitment Therapy, and A Functional Analytic Definition of Mindfulness. Journal of Public Health, 100. 12. 23722378 .

Friedenberg, Lisa. 1995. Psychological Testing, Design, Analysis, and Use. USA: Allyn and Bacon.

Glesne, Corrine. 2011. Becoming Qualitative Researchers: An Introduction $4^{\text {th }}$ Edition. Boston: Pearson.

Graziano, Anthony \& Raulin, M.L. 2000. Research Method: A Process of Inquiry $4^{\text {th }}$ Edition. New York: Addison Wesley Educational Publisher Inc. Higgins.

Hallahan, D.P., Kaufman, J.M., \& Pullen, P.C. 2009. Exceptional Learners: An Introduction to Special Education. USA: Pearson Education.

Harris, Russell. 2009. Acceptance and Commitment Therapy Training. Retrieved from

http://www.actmindfully.com.au/ac ceptance_\&_commitment_therapy on Desember 2016.

Harris, Russell. 2016. Embracing Your Demons: An Overview of Acceptance and Commitment Therapy. Journal of Psychoterapy In Australia, Vol. 12, 4, 2-8.

Hayes, S.C. 2005. Get Out of Your Mind and Into Your Life: The New Acceptance and Commitment Therapy. Oakland: New Harbiger Publication, Inc.

Hayes, S.C., et.al. 1999. Acceptance Commitment Therapy: An Experimental Approach to Behavior Change. New York: The Guilford Press.
Hayes, S.C., et.al. 2006. Acceptance and Commitment Therapy: Model, Process, and Outcomes. USA: Psychology Faculty Publication.

Hayes, S.C., Strosahl, K.D. 2004. What is Acceptance and Commitment Therapy. Dalam "A Practical Guide to Acceptance and Commitment Therapy" Selected Reading hlm 3 - 29. New York: Springer.

Kohls, L.R., Brussow, H.L., 1995. Training Know How for Cross Cultural and Diversity Trainers. San Fransisco: Adult Learning Systems.

Lazarus, R., Folkman, S. 1984. Stress, Appraisal, and Coping. New York: Springer Publishing Company.

Lazarus, R.S. 1999. Stress and Emotion: A New Synthesis. New York: Springer.

Mangunson, F. 2009. Psikologi dan Pendidikan Anak Berkebutuban Kbusus. Depok: LPSP3 Fakultas Psikologi Universitas Indonesia.

Martirosyan, A. 2013. Sibling Relationships in Families with A Child with Special Needs: A Case Study of A Norwegian Family With A Child With Down Syndrome And Her Three Sibling(s). Thesis. Oslo: Department of Special Needs Education, Faculty of Educational Sciences University of Oslo.

Mash, E. J., Wolfe, D. A. 2010. Abnormal Child Psychology. USA: Wadsworth, Cengage Learning.

Papalia, D.E., Olds, S.W., Feldman, R.D. 2004. Human Development $9^{\text {th }}$ Edition. New York: McGrew-Hill.

Santrock, J.2. 2014. Adolescence (15 th Edition). New York: McGraw Hill.

Sarafino, E.P., Smith, T.W. 2012. Health Psychology Biopsychosocial Interaction $7^{\text {th }}$ Edition. USA: John Wiley \& Sons, Inc. 
Seniati, L., Yulianto, A., Setiadi, B.N. 2005. Psikologi Eksperimen. Jakata: PT. Indeks.

Smouth, M. 2012. Acceptance and Commitment Therapy: Pathways for General Practitioners. Australian Family Physiction, Vol.41, 672-676.

Springer, J.M. 2012. Acceptance and Commitment Therapy: Part of The "Third Wave" In The Behavioral Tradition. Journal of Mental Health Counseling, Vol. 34, 3, 205-212.

Sullivan, M. 2002. Sibling(s) of Children with Down Syndrome and Their Perceptions of Family Functioning. Thesis. Retireved from Proquest on Desember 2016.

Taylor, S.E. 2012. Health Psychology $8^{\text {th }}$ Edition. New York: McGraw-Hill.

Walker, J. 2002. Teens in Distress Series Adolescent Stress and Depression. Retrieved from http://www.smmusd.org/Samohi/P TSA/minutes/teens_in_distress.html on Desember 2016.

Walker, L.R. 2007. Retrieved from http://www.preventionworkinseattle .org on Desember 2016.

Wicksell, R.K., Magnusson, B. 2005. Using Acceptance and Commitment Therapy in the Rehabilitation of an Adolescent Female with Chronic Pain: A Case Example. Cognitive and Behavioral Practice, Vol 12, 415-423.

Wicks-Nelson, R., \& Israel, A. 2009. Abnormal Child and Adolescent Psychology. New Jersey: Pearson Education.

Wilkerson, Robin Rider. 2001. The Adolescence's Experience of Having a Sibling with Down Syndrome. Disertasi. Retrieved from Proquest on 21 November 2016.

Williams, K.E., Ciarrochi, J., Heaven, P.C.I. 2012. Inflexible Parents, Inflexible Kids: Psychological Flexibility in
Adolesents. Journal of Youth and Adolesence, 41, 1053-1066. 